\title{
Long-term outcomes and determinants of stenosis recurrence after renal artery angioplasty in hypertensive patients with renovascular disease
}

\author{
Agnieszka Rosławiecka , Anna Kabłak-Ziembicka², Rafał Badacz², Daniel Rzeźnik ${ }^{1}$, Piotr Pieniążek³ \\ Mariusz Trystuła4, Tadeusz Przewłocki ${ }^{3}$ \\ ${ }^{1}$ Department of Interventional Cardiology, John Paul II Hospital, Krakow, Poland \\ ${ }^{2}$ Department of Interventional Cardiology, Jagiellonian University Medical College, John Paul II Hospital, Krakow, Poland \\ ${ }^{3}$ Department of Diseases of Cardiac and Vessels, Jagiellonian University Medical College, John Paul II Hospital, Krakow, Poland \\ ${ }^{4}$ Department of Vascular Surgery with Division of Endovascular Interventions, John Paul II Hospital, Krakow, Poland
}

Adv Interv Cardiol 2020; 16, 1 (59): 65-75

DOI: https://doi.org/10.5114/aic.2019.91309

\section{A bstract}

Introduction: Restenosis (RS) following percutaneous angioplasty (PTA) of renal artery stenosis (RAS) might have an unfavourable impact on renal function and blood pressure (BP) outcomes.

Aim: To evaluate the prevalence and predictors of RS in patients treated with PTA for RAS, and the relationship between BP and renal function (RF) changes with RS.

Material and methods: We analysed freedom from RS in 210 patients (age $64.6 \pm 12.8$ years; range: $20-85$ ), who underwent 248 successful stent-assisted PTAs in RAS. The change in levels of serum creatinine (SCC), estimated glomerular filtration rate (eGFR), systolic/diastolic BPs (SBP/DBP) were analysed prior to PTA, at 6-, 12-month, and final follow-up visits, and whenever RS was diagnosed.

Results: RS was identified in 30 (14.3\%) patients, and there were 36 (14.5\%) lesions. The Kaplan-Meier RS-free survival curves in fibromuscular dysplasia, atherosclerosis, and vasculitis at 1 and 7 years were: $100 \%$ and $100 \%$; 95.6 and $83.9 \%$; and 71.4 and $39.7 \%$, respectively. Patients with RS, as compared to RS-free patients, presented with less pronounced changes in respect with: SBP $(1.4 \pm 17.6$ vs. $-15.8 \pm 25.8 \mathrm{~mm} \mathrm{Hg} ; p=0.01)$, DBP $(2.64 \pm 10.1$ vs. $-6.5 \pm 14.1 \mathrm{~mm} \mathrm{Hg} ; p=0.002)$, SCC $(22.4 \pm 55.2$ vs. -3.6 $\pm 43.9 \mu \mathrm{mol} / \mathrm{l} ; p=0.002)$, and eGFR $(-1.85 \pm 18 \mathrm{vs} .-5.34 \pm 19.5 \mathrm{~mm} \mathrm{Hg} ; p=0.045)$. In multivariate Cox regression analysis, independent predictors of RS occurred: lack of BP decrease (HR $=4.19,95 \% \mathrm{Cl}: 1.67-10.3 ; p=0.002)$, eGFR increase $<0.17 \mathrm{ml} / \mathrm{min} / 1.73 \mathrm{~m}^{2}$ $(\mathrm{HR}=2.93,95 \% \mathrm{Cl}: 1.08-7.91 ; p=0.033)$, stent diameter $\leq 5 \mathrm{~mm}(\mathrm{HR}=2.76,95 \% \mathrm{Cl}: 1.09-6.97 ; p=0.031)$, and vasculitis $(\mathrm{HR}=5.61,95 \% \mathrm{Cl}: 1.83-17.2 ; p=0.003)$. RS was treated in 24 patients with $\mathrm{RS}$ recurrence in $20 \%$.

Conclusions: The RS rate differs depending on RAS aetiology. Lack of SBP/DBP and eGFR improvement, vasculitis, and stent diameter are associated with RS risk. Repeated PTA is effective, but recurrent RS occurs in $20 \%$ of cases.

Key words: renal artery endovascular treatment, restenosis incidence, predictors of restenosis, primary and secondary patency.

\section{Su m m a ry}

Restenosis (RS) following percutaneous angioplasty (PTA) of renal artery stenosis (RAS) might have an unfavourable impact on renal function and blood pressure (BP) outcomes. We demonstrated in a group of 210 patients with 248 treated lesions, who underwent successful PTA procedure for RAS, that the average RS rate was $14 \%$, accounting for $60 \%$ in inflammatory, $17 \%$ in atherosclerotic, and $0 \%$ in fibromuscular dysplasia RAS. Lack of the systolic blood pressure/diastolic blood pressure and estimated glomerular filtration rate improvement following PTA, as well as inflammatory aetiology and lower stent diameter, were associated with 4.19-, 2.93- 5.61-, and 2.76-fold risk increase of RS, respectively. Repeated PTA was effective, but recurrent RS occurred in $20 \%$ of cases.

\section{Corresponding author:}

Prof. Tadeusz Przewłocki MD, PhD, Department of Diseases of Cardiac and Vessels, Jagiellonian University Medical College, John Paul II Hospital, 80 Prądnicka St, 31-202 Krakow, Poland, phone: +48 504299 362, e-mail: tadeuszprzewlocki@op.pl Received: 10.09.2019, accepted: 21.10.2019. 


\section{Introduction}

Percutaneous transluminal angioplasty (PTA) is a therapeutic option in patients with symptomatic renal artery stenosis (RAS) [1-3]. In fibromuscular dysplasia (FMD) this kind of treatment is the first-line therapy, whereas in atherosclerotic stenosis indications for PTA are limited to special clinical settings. The use of stents is determined by the RAS aetiology and anatomy $[3,4]$.

The immediate result of PTA is characterised by a high success rate and fairly low periprocedural complication rate [5-7]. However, the clinical improvement following PTA of RAS is uncertain [5-8]. The effect of PTA is probably a complex issue, as both the effect of PTA on renal function and systolic/diastolic blood pressure (SBP/ DBP), as well as cardiovascular adverse events is at least controversial $[6,9,10]$. Furthermore, the long-term result of PTA is limited by the unwelcome occurrence of recurrent stenosis (RS) that may additionally impact the final effect of PTA. The RS rate following RAS procedures is estimated at $6-40 \%[5-8,11]$. However, the determinants of RS are poorly established.

Among the potential risk factors of RS following PTA, the RAS aetiology, the presence of previous cardiovascular disease, RAS severity exceeding $90 \%$, bare metal stent (BMS) use, or renal artery reference calibre are mentioned [12-14]. Protective use of statins before PTA was postulated [15]. Nevertheless, data concerning the determinants of RS following PTA for RAS are rather inconsistent and poorly demonstrated.

Furthermore, the optimal treatment of RS has not been established. Potential treatment options include: balloon angioplasty with or without drug coating, cutting balloon angioplasty or deployment of a second conventional stent, repeat stenting with drug-eluting stents, or endovascular brachytherapy [16-18]. Other innovative modalities include: polytetrafluoroethylene (PTFE)-covered stents or carbon coating stents [16-18]. However, their long-term effects remain unknown.

\section{Aim}

Therefore, the aim of our study was to determine predictors of primary RS and the results of RS treatment in patients with symptomatic RAS following endovascular treatment.

\section{Material and methods}

In this prospective all-comers study, 210 patients aged $64.6 \pm 12.8$ years $(20-85)$ underwent 248 successful PTAs of RAS, with or without stent implantation. Thirty-nine patients underwent bilateral PTAs. We analysed freedom from the RS in index lesion.

Inclusion criteria were de novo unilateral or bilateral RAS of at least $60 \%$ with either accelerated hypertension despite three or more blood lowering medications, includ- ing at least one diuretic, drug-resistant hypertension (SBP and/or DBP values of > $140 \mathrm{~mm} \mathrm{Hg}$ and/or $90 \mathrm{~mm} \mathrm{Hg}$, respectively), despite the aforementioned pharmacological treatment, and/or hypertension crisis.

Also, patients with progressive renal impairment and/or episode of acute renal failure associated with angiotensin-converting enzyme inhibitor (ACEI) treatment were included in the present study. Other inclusion criteria were pulmonary flash oedema, congestive heart failure, or severe angina/acute coronary syndrome that could not been explained by coronary artery status.

Patients with well controlled BP on blood lowering agents or renal atrophy (kidney length $<7 \mathrm{~cm}$ in women and $<8 \mathrm{~cm}$ in men), and patients not willing to participate in the study or with a follow-up period shorter than 6 months following PTA were excluded from the present study.

The prevalence of the cardiovascular risk factors was evaluated. Blood samplings for renal function assessment were collected on patient admission to the department, prior to any intervention, immediately after signed, informed consent was obtained from the patients.

Baseline and the change in levels of serum creatinine (SCC), eGFR, SBP, and DBP as well as the number of blood lowering regiments were analysed prior to PTA, at 12-month and final follow-up (F-U) visits, and whenever at the point of RS diagnosis.

The glomerular filtration rate was estimated from the Modification of Diet in Renal Disease (MDRD) formula, according to following equation: MDRD $=175 \times$ creatinine $[\mathrm{mg} / \mathrm{dl}]-1.154 \times$ age [years] $-0.203 \times 0.742$ [if female] .

SBP and DBP measurements were performed in compliance with the Seventh Report of the Joint National Committee on Prevention, Detection, Evaluation, and Treatment of High Blood Pressure: the JNC 7 report published in 2003 and ESH/ESC Guidelines for the management of arterial hypertension published in 2013 [19, 20]. In brief, the mean SBP and DBP value was averaged from at least two BP measurements, preceded by 5 min of rest and repeated within a two-minute interval.

The study protocol was reviewed and approved by the Local Ethical Committee. All the patients gave their informed consent for participation in the study. The study was performed in accordance with the Declaration of Helsinki.

\section{Revascularisation procedure for RAS}

Renal angiography was performed from radial or femoral vascular access using a Coroscop system (Siemens AG, Munich, Germany) equipped with Quantcor version 4.0 quantitative analysis software. Angiography was performed in two modified projections that best displayed the lesion. Eligibility criteria were determined on the basis of contemporary published guidelines for percutaneous revascularisation of the RAS [1-3]. 
Patients were premedicated with a loading dose of aspirin of $300 \mathrm{mg}$, followed by $75 \mathrm{mg}$ /day given indefinitely, and a loading dose of clopidogrel of $300 \mathrm{mg}$, followed by $75 \mathrm{mg} /$ day for 1 to 6 months. During the procedure unfractionated heparin was administrated according to patient weight and ACT. Periprocedurally, routinely patients were given 1.5-2.0 I of fluids IV to prevent contrast-induced nephropathy.

The significance of RAS was determined by quantitative angiography (COROSCOP, Siemens, and Quantcor QCA V4.0 software for quantitative analysis, Erlangen, Germany). An RAS range of $50-69 \%$ of diameter of stenosis was assumed borderline, and additional invasive criteria were taken into consideration to confirm RAS significance (resting mean translesional pressure gradient $>10 \mathrm{~mm} \mathrm{Hg}$, systolic pressure gradient > $20 \mathrm{~mm} \mathrm{Hg}$, or renal fractional flow reserve induced by dopamine $50 \mu \mathrm{g} / \mathrm{kg}$, rFFR $\leq 0.8$ ).

The first-line revascularisation technique in FMD-related RAS was PTA without stenting. Atherosclerotic lesions were treated with PTA with stent implantation, and a renal protection device was used in 1 case. RAS caused by vasculitis was managed with stenting, favouring drug eluting stent (DES) implantation. DES was also preferred in patients with a single functioning kidney, small vessel diameter, and when the patient had a history of restenotic lesion in the other arterial bed.

Balloons were sized to the diameter of the reference segment of the vessel, and the patient's symptoms were assessed during each balloon inflation.

During revascularisation procedure, predilatation vs. direct stenting technique depended on the clinical circumstances and the operator's decision. In all cases with stent implantation, a balloon expandable stent was used. The choice of stent was conditioned by the operator's decision, taking into account a variety of factors such as vessel anatomy, treated lesion, and stent availability. As a consequence, a heterogeneous group of stents was implanted. Procedural success was defined as residual diameter stenosis less than $30 \%$.

RS was defined as recurrence of at least $50 \%$ reduction of the arterial lumen diameter within the stent or the adjacent $5 \mathrm{~mm}$ of vessel segments. When symptomatic RS was confirmed the patient was refed for repeated revascularisation.

Primary patency was defined as patency of the target lesion following endovascular intervention, and secondary patency as the final patency of the target lesion after re-intervention.

\section{Follow-up period}

The study participants were evaluated at 6 and 12 months after the procedure in the outpatient setting. Thereafter, the assessment was performed at yearly in tervals. The follow-up evaluation included clinical assess- ment, blood pressure and renal function measurement, and duplex ultrasonography (DUS). If the patient died between month 6 and 12, the parameters from the last follow-up visit were taken into statistical analysis.

Hypertension cure was defined as BP values below $140 / 90 \mathrm{~mm} \mathrm{Hg}$ in patients with withdrawn hypertensive medications.

During the median observation period of $48(\mathrm{Q} 1$; Q3: 23; 80) months, the incidences and predictors of RS, treatment for RS, and recurrent RS were analysed.

RS was initially diagnosed with DUS based on the peak-systolic aortic and renal artery velocities and intra-renal flow parameters [21]. The RAS was confirmed with either CT-angiography or directly during the invasive angiography preceding the PTA procedure. In some patients stenosis severity was established with translesional resting and hyperaemic gradients. Data on RS were collected during the follow-up visits.

\section{Statistical analysis}

The Student's $t$-test was used for comparison of continuous variables, and a $\chi^{2}$ test was used to compare proportions of categorical variables. Means of the analysed parameters across groups were tested by analysis of variance test. Frequencies were compared by $\chi^{2}$ test for independence.

We analysed the influence of renal function and BP parameter changes, as well as patient-and procedure-related factors on the incidence of RS and recurrent RS. To ensure reliable cut-off values of BP and renal function parameter changes, which were potentially associated with risk of RS, Receiver Operating Characteristic (ROC) curves were constructed. The area under the ROC curve (AUC) was calculated as well as the $95 \%$ confidence interval $(\mathrm{CI})$. The ROC analysis was followed by the uni- and multivariate Cox model.

To establish the factors that could affect RS incidence, the clinical, procedural, and angiographic variables were assessed by a Cox univariate hazard analysis, and in cases with a trend toward a difference $(p<0.15)$, they were included in a multivariate stepwise Cox proportional hazards analysis. The results of the multivariate Cox proportional hazards analysis were expressed as hazard ratio (HR) and 95\% confidence interval (Cl).

Seven-year Kaplan-Meier RS-free survival curves for primary and secondary target lesion patency, as well as RS rate depending on RAS aetiology were constructed.

Statistical analyses were performed with Statistica version 13.0 software (StatSoft, Inc., Tulsa, OK). $P<0.05$ was considered statistically significant.

\section{Results}

Baseline clinical and procedural characteristics of the study participants are presented in Table I. In brief, out of 210 patients with 248 lesions referred to PTA, 225 
Table I. Baseline clinical and procedural characteristics of the study participants $(n=210)$

\begin{tabular}{|c|c|}
\hline Parameter & Value \\
\hline Age, mean \pm SD (range) [years] & $64.6 \pm 12.8(20-85)$ \\
\hline Men, $n(\%)$ & $109(51.9)$ \\
\hline \multicolumn{2}{|l|}{ RAS aetiology, $n(\%)$ : } \\
\hline Atherosclerosis & $192(91.4)$ \\
\hline Fibromuscular dysplasia & $6(2.9)$ \\
\hline Vasculitis & $8(3.8)$ \\
\hline Other (vessel injury) & $4(1.9)$ \\
\hline Hypertension, $n(\%)$ & $210(100)$ \\
\hline Diabetes mellitus, $n(\%)$ & $63(30)$ \\
\hline Hyperlipidaemia, $n$ (\%) & $192(91.4)$ \\
\hline Smoking history, $n(\%)$ & $92(43.8)$ \\
\hline $\begin{array}{l}\text { Renal impairment with } \\
\text { eGFR* }<60 \mathrm{ml} / \mathrm{min} / 1.73 \mathrm{~m}^{2}, n(\%)\end{array}$ & $125(59.2)$ \\
\hline Previous myocardial infarction, $n$ (\%) & $32(15.2)$ \\
\hline $\begin{array}{l}\text { Previous coronary revascularisation } \\
\left(\mathrm{PCl}, \mathrm{CABG}^{\star \star}\right), n(\%)\end{array}$ & $89(42.3)$ \\
\hline Previous peripheral revascularisation, $n(\%)$ & $56(26.6)$ \\
\hline $\begin{array}{l}\text { Previous ischaemic stroke /transient } \\
\text { ischaemic attack, } n(\%)\end{array}$ & $22(10.4)$ \\
\hline Coronary artery disease, $n(\%)$ & $138(65.7)$ \\
\hline $\begin{array}{l}\text { Carotid, vertebral or subclavian artery }>50 \% \\
\text { lumen diameter stenosis, } n(\%)\end{array}$ & $89(42.4)$ \\
\hline \multicolumn{2}{|c|}{ Lesions characteristics and primary procedure overview $(n=248)$ : } \\
\hline Unilateral PTA, $n$ (\%) & $139(66.2)$ \\
\hline Bilateral PTA, $n$ (\%) & $39(18.6)$ \\
\hline $\begin{array}{l}\text { PTA of the artery supplying one functioning } \\
\text { kidney RAS, } n(\%)\end{array}$ & $32(15.2)$ \\
\hline RAS of right renal artery, $n(\%)$ & $121(48.8)$ \\
\hline RAS of left renal artery, $n(\%)$ & $127(51.2)$ \\
\hline $\begin{array}{l}\text { Mean stenosis severity before PTA, } \\
\text { mean } \pm \text { SD, (range) (\%) }\end{array}$ & $\begin{array}{c}73.6 \pm 15.5 \\
(50-100)\end{array}$ \\
\hline $\begin{array}{l}\text { Mean stenosis severity after primary PTA, } \\
\text { mean } \pm \text { SD, (range) (\%) }\end{array}$ & $13.5 \pm 8.5(1-40)$ \\
\hline Transfemoral access, $n(\%)$ & $239(96.4)$ \\
\hline Radial/brachial access, $n(\%)$ & $5(2)$ \\
\hline Double access (staged procedure), $n(\%)$ & $4(1.6)$ \\
\hline $\begin{array}{l}\text { Balloon angioplasty alone (per successful } \\
\text { PTA/per patient), } n(\%)\end{array}$ & $11(4.4) / 8(3.8)$ \\
\hline Stent implantation, $n(\%)$ & $237(95.5)$ \\
\hline Drug-eluting stent implantation, $n(\%)$ & $25(10.5)$ \\
\hline Bare metal stent implantation, $n(\%)$ & $212(85.5)$ \\
\hline $\begin{array}{l}1 \text { stent for one lesion (per stent } \\
\text { implantation), } n(\%)\end{array}$ & 227/237 (95.8) \\
\hline $\begin{array}{l}\geq 2 \text { stents for one lesion (per stent } \\
\text { implantation), } n(\%)\end{array}$ & $10 / 237(4.2)$ \\
\hline Mean stent length, mean \pm SD (range) [mm] & $16.2 \pm 4(7-36)$ \\
\hline $\begin{array}{l}\text { Mean stent diameter, mean } \pm \text { SD (range) } \\
{[\mathrm{mm}]}\end{array}$ & $5.6 \pm 1.4(3.0-8.0)$ \\
\hline Direct stenting (per stent implantation), $n(\%)$ & $155(65.4)$ \\
\hline Predilatation (per stent implantation), $n(\%)$ & $82(34.6)$ \\
\hline
\end{tabular}

eGFR - glomerular filtration rate estimated by MDRD formula. $P C l$ - percutaneous coronary intervention, $C A B G$ - coronary artery bypass grafting.
(90.8\%) lesions were diagnosed with atherosclerosis, 9 (3.6\%) with fibromuscular dysplasia (FMD), 10 (4\%) with vasculitis, and the remaining 4 (1.6\%) with trauma-related vessel injury resulting in RAS. All FMD-related lesions underwent successful balloon angioplasty without stenting because there was no indication for stent implantation after balloon angioplasty. All arteritis-related lesions were stented, while only two atherosclerosis-related RAS underwent plain balloon angioplasty.

Arterial hypertension was diagnosed in all subjects, while renal failure $\left(e G F R<60 \mathrm{ml} / \mathrm{min} / 1.73 \mathrm{~m}^{2}\right.$ ) was diagnosed in 125 (59.2\%) patients. Unilateral PTA was performed in 139 (66.2\%) patients, and bilateral or PTA of the one functioning kidney in 39 (18.6\%) and 32 (15.2\%) patients, respectively. The mean stenosis diameter before PTA in the whole study group was $73.6 \pm 15.5 \%$, and it was reduced to $13.5 \pm 8.5 \%$ post PTA. In particular, the stenosis degree was reduced from $80.4 \pm 30 \%$ to $11.6 \pm 12 \%$ in arteritis-related RAS, from $73.5 \pm 13.9 \%$ to $13.9 \pm 9.3 \%$ in atherosclerotic RAS, and from $75.1 \pm 10$ to $12 \pm 9 \%$ in FMD-related lesions ( $p=N S$ ). DES were implanted in $25(10.1 \%)$ and BMS in 212 (85.5\%), while plain balloon alone as the ultimate method of revascularisation was performed in 11 (4.4\%) lesions.

Median follow-up was 48 months (Q1, Q3: 23, 80 months). Mean SBP and DBP values after PTA, as compared to baseline values, were significantly reduced from $150.2 \pm 24.6$ to $132.2 \pm 18.2 \mathrm{~mm} \mathrm{Hg}(p<0.001)$, and from $82.5 \pm 13.4$ to $75.4 \pm 11.5 \mathrm{~mm} \mathrm{Hg}(p<0.001)$, respectively. Also, the number of blood lowering agents was reduced significantly from $3.5 \pm 1.3$ to $3.2 \pm 1.4$ ( $p=0.003$ ) (Figure 1). In line, significant mean eGFR increased from 54.5 \pm 23 to $59.4 \pm 3.9 \mathrm{ml} / \mathrm{min} / 1.73 \mathrm{~m}^{2}(p=0.001)$, but no SCC $(p=0.299)$ were observed (Figure 1$)$.

During the follow-up period, RS was identified in 36 revascularized vessels, in 30 (14.4\%) patients. Patients with diagnosed RS in comparison to the non-RS group were characterised by higher prevalence of hyperlipidaemia $(p=0.007)$ and diabetes $(p=0.07)$, inflammatory aetiology of revascularised lesion $(p<0.002)$, use of predilatation $(p=0.006)$, and more frequently had lower stent diameter $(p=0.001)$ (Table II).

Patients at the point of RS identification, as compared to RS-free patients, presented with lack of clinical response in terms of changes in SBP $(1.4 \pm 17.6$ vs. -15.8 $\pm 25.8 \mathrm{~mm} \mathrm{Hg} ; p=0.01)$ and DBP (2.64 \pm 10.1 vs. -6.5 $\pm 14.1 \mathrm{~mm} \mathrm{Hg} ; p=0.002)$ and clear noticeable deterioration of renal function: SCC $(22.4 \pm 55.2$ vs. $-3.6 \pm 43.9$ $\mu \mathrm{mol} / \mathrm{l} ; p=0.002)$, as well as eGFR $(-1.85 \pm 18$ vs. -5.34 $\pm 19.5 \mathrm{~mm} \mathrm{Hg} ; p=0.045$ ) (Table III).

SBP decrease of less than $-1 \mathrm{~mm} \mathrm{Hg}(\mathrm{AUC}=0.778$; 95\% Cl: $0.66-0.86 ; p<0.001$; sensitivity: $75 \%$; specificity: $77 \%$ ), DBP less than $-2 \mathrm{~mm} \mathrm{Hg}$ (AUC = 0.720; 95\% Cl: $0.63-0.81 ; p<0.001$; sensitivity: 77\%; speci- 
A

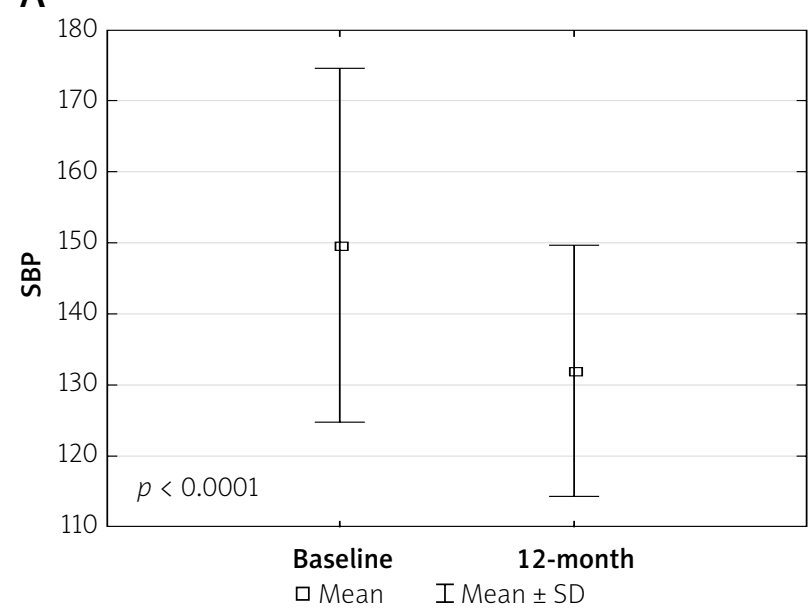

C

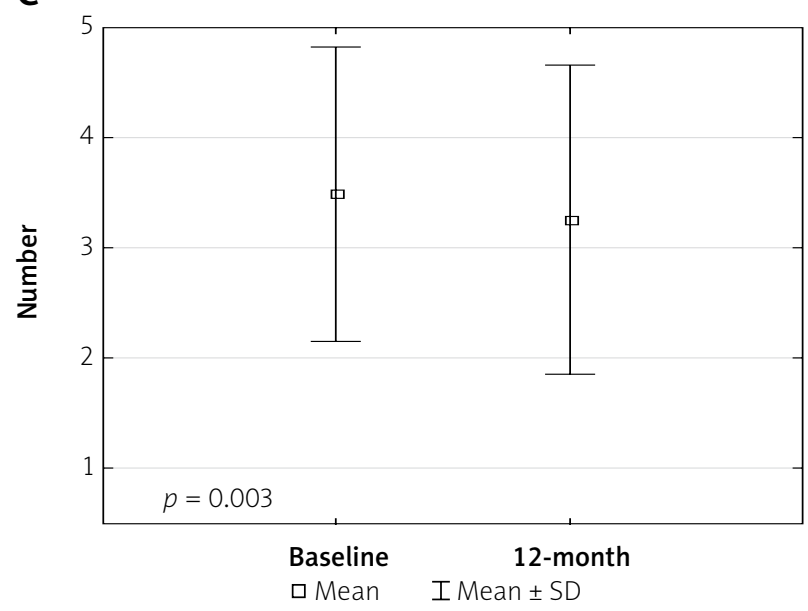

$\mathrm{E}$

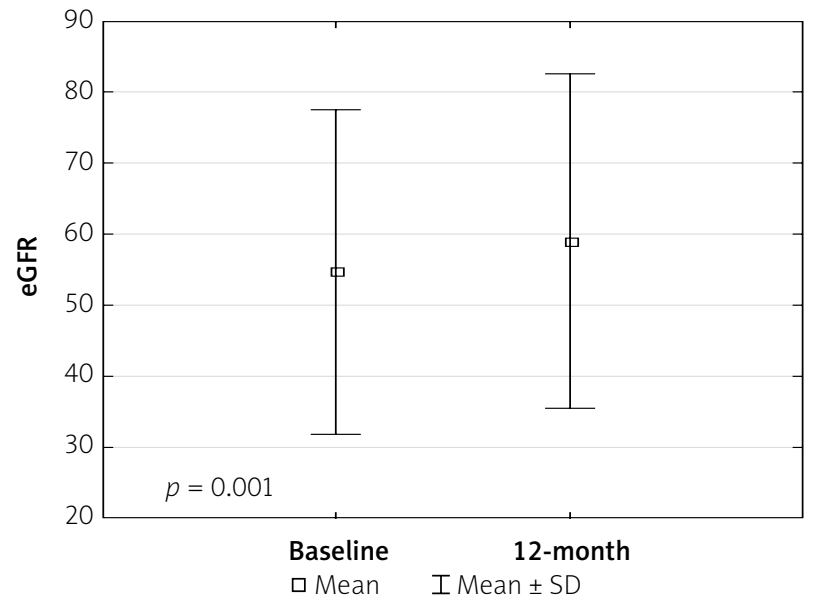

ficity: $63 \%$ ), SCC increase of $22 \mu \mathrm{mol} / / \mathrm{l}$ (AUC $=0.621$; 95\% Cl: 0.51-0.72; $p=0.019$ ), as well as no decrease of eGFR (AUC $=0.621 ; 95 \% \mathrm{Cl}: 0.51-0.72 ; p=0.020$ ), and stent diameter equal or lower than $5 \mathrm{~mm}$ ( $\mathrm{AUC}=0.683$; $95 \% \mathrm{Cl}: 0.58-0.77 ; p=0.002$ ) were identified as the best cut-off values to discriminate the risk of RS by the ROC
B

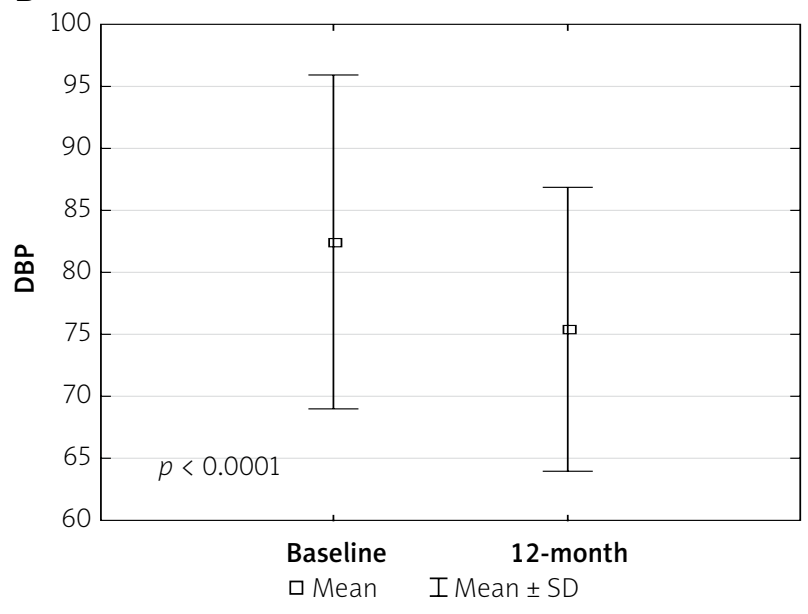

D

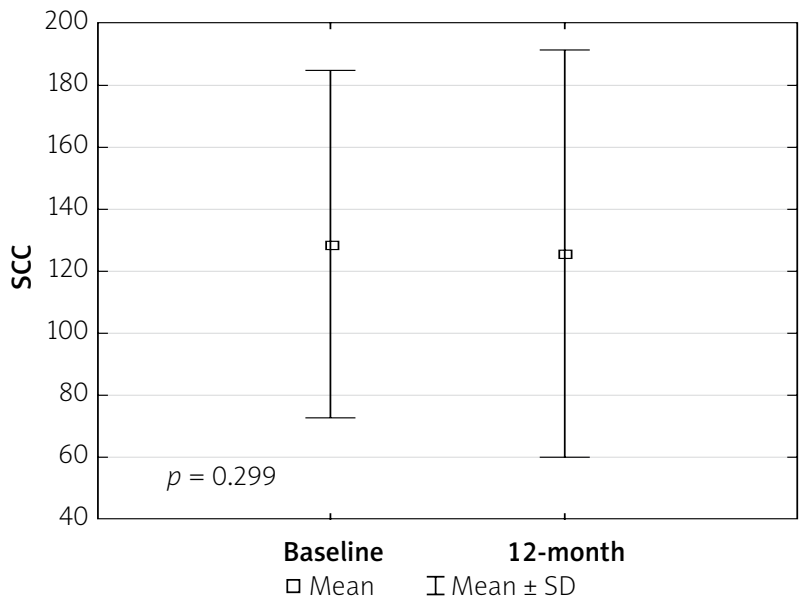

Figure 1. Baseline vs. 12-month values for: A - systolic blood pressure (SBP), $\mathrm{B}$ - diastolic blood pressure (DBP), $\mathbf{C}$ - number of blood lowering medications, D - serum creatinine concentration (SCC), E - estimated glomerular filtration rate (eGFR) by MDR formula

analysis. These cut-off values were analysed with univariate Cox proportional hazard analysis initially, followed by the multivariate Cox analysis (Table IV).

In multivariate Cox regression analysis: lack of BP decrease ( $\mathrm{HR}=4.19,95 \% \mathrm{Cl}: 1.67-10.3 ; p=0.002)$, eGFR increase less than $0.17 \mathrm{ml} / \mathrm{min} / 1.73 \mathrm{~m}^{2}(H R=2.93$; 
Table II. Comparison of clinical, angiographic, and procedural data in patients and lesions with RS $(n=30 / 36)$ and without RS $(n=180 / 212)$

\section{Patients' characteristics}

\begin{tabular}{l}
\hline Age, mean \pm SD (range) [years] \\
\hline Male gender, $n$ (\%) \\
\hline Coronary artery disease, $n$ (\%) \\
\hline Supra-aortic involvement, $n$ (\%) \\
\hline Peripheral artery disease, $n$ (\%) \\
\hline History of myocardial infarction, $n$ (\%) \\
\hline History of ischemic stroke/TIA, $n$ (\%) \\
\hline History of percutaneous coronary intervention, $n$ (\%) \\
\hline History of CABG, $n$ (\%) \\
\hline History of peripheral artery endovascular treatment, $n(\%)$ \\
\hline Hypertension, $n$ (\%) \\
\hline Diabetes mellitus, $n$ (\%) \\
\hline Hyperlipidaemia, $n$ (\%) \\
\hline Smoking history, $n$ (\%) \\
\hline Renal impairment with eGFR* $<60$ ml/min/1.73 m², $n$ (\%) \\
\hline RAS aetiology (per lesion): \\
\hline Atherosclerosis, $n$ (\%) \\
\hline Fibromuscular dysplasia, $n(\%)$ \\
\hline
\end{tabular}

\begin{tabular}{|c|c|c|}
\hline $\begin{array}{l}\text { Patients with RS } \\
\quad(n=30)\end{array}$ & $\begin{array}{l}\text { Patients without RS } \\
\quad(n=180)\end{array}$ & $P$-value \\
\hline $62.2 \pm 14.9$ & $64.8 \pm 11.5$ & 0.291 \\
\hline $14(46.7)$ & 95 (52.7) & 0.806 \\
\hline $19(63.3)$ & 119 (66.1) & 0.840 \\
\hline $15(50)$ & $74(41.1)$ & 0.525 \\
\hline $6(20)$ & $59(32.8)$ & 0.073 \\
\hline $4(13.3)$ & 28 (15.6) & 0.815 \\
\hline $3(10)$ & 19 (10.6) & 0.980 \\
\hline $12(40)$ & $54(30)$ & 0.246 \\
\hline $5(16.7)$ & $29(16.1)$ & 0.878 \\
\hline $7(23.3)$ & $41(22.8)$ & 0.753 \\
\hline $30(100)$ & $180(100)$ & 1 \\
\hline $12(40)$ & $51(28.3)$ & 0.070 \\
\hline $24(80)$ & $173(96.1)$ & $<0.001$ \\
\hline $11(36.7)$ & $81(45)$ & 0.491 \\
\hline \multirow[t]{2}{*}{$14(46.7)$} & 111 (61.7) & 0.494 \\
\hline & & $<0.001$ \\
\hline $30(83.4)$ & 195 (92) & \\
\hline $0(0)$ & $9(4.2)$ & \\
\hline $5(13.8)$ & $5(2.4)$ & \\
\hline $1(2.8)$ & $3(1.4)$ & \\
\hline
\end{tabular}

\begin{tabular}{|c|c|c|c|}
\hline Lesions' characteristics & $\begin{array}{c}\text { Restenotic lesions } \\
(n=36)\end{array}$ & $\begin{array}{l}\text { Non-restenotic } \\
\text { lesions }(n=212)\end{array}$ & $P$-value \\
\hline Right renal artery disease treated with PTA, $n(\%)$ & $17(47.2)$ & $104(49.1)$ & 0.819 \\
\hline Left renal artery disease treated with PTA, $n(\%)$ & $19(52.8)$ & $108(50.9)$ & \\
\hline \multicolumn{4}{|l|}{ Mean degree of stenosis (\%): } \\
\hline Before primary PTA, mean \pm SD (range) & $74 \pm 19.5(50-100)$ & $73.6 \pm 14(50-100)$ & 0.462 \\
\hline After primary PTA, mean \pm SD (range) & $16.3 \pm 11.1(3-40)$ & $13.4 \pm 9.2(1-33)$ & 0.428 \\
\hline DES implantation (per stenting), $n(\%)$ & $3(12)$ & $22(88)$ & 0.632 \\
\hline Bare metal stent implantation (per stenting), $n$ (\%) & $33(15.6)$ & $179(84.4)$ & \\
\hline 1 stent for one lesion (per stent implantation), $n$ (\%) & $34(94.4)$ & $193(96)$ & 0.670 \\
\hline$\geq 2$ stents for one lesion (per stent implantation), $n(\%)$ & $2(5.6)$ & $8(4)$ & \\
\hline Mean stent length \pm SD (range) $[\mathrm{mm}]$ & $15.3 \pm 4.9(7-36)$ & $16.4 \pm 3.7(12-34)$ & 0.555 \\
\hline Mean stent diameter \pm SD (range) $[\mathrm{mm}]$ & $5.3 \pm 1(3.0-8.0)$ & $5.6 \pm 1.3(4.5-8)$ & 0.001 \\
\hline Maximal inflation pressure \pm SD (range) [atm] & $14.4 \pm 3.8(8-25)$ & $13.9 \pm 2.8(8-22)$ & 0.054 \\
\hline Direct stenting (per stent implantation), $n(\%)$ & $17(47.2)$ & $140(69.6)$ & 0.058 \\
\hline Predilatation (per stent implantation), $n$ (\%) & $19(52.8)$ & $61(30.4)$ & 0.006 \\
\hline
\end{tabular}


Table III. Comparison of baseline and follow-up parameters of renal function and blood pressure in groups with and without restenosis

\begin{tabular}{|c|c|c|c|}
\hline Baseline renal function and blood pressure & $\begin{array}{l}\text { Patients with RS } \\
\qquad(n=30)\end{array}$ & $\begin{array}{l}\text { Patients without RS } \\
\qquad(n=180)\end{array}$ & $P$-value \\
\hline Initial creatinine level, mean \pm SD $[\mu \mathrm{mol} / \mathrm{l}]$ & $128.6 \pm 55$ & $129.4 \pm 59.3$ & 0.937 \\
\hline Initial eGFR, mean \pm SD $\left[\mathrm{ml} / \mathrm{min} / 1.73 \mathrm{~m}^{2}\right]$ & $55.8 \pm 26.5$ & $53.7 \pm 22.2$ & 0.626 \\
\hline Initial systolic blood pressure, mean \pm SD [mm Hg] & $146.9 \pm 17.3$ & $150.9 \pm 25.2$ & 0.408 \\
\hline Initial diastolic blood pressure, mean \pm SD [mm Hg] & $79.7 \pm 12.7$ & $83.1 \pm 13.2$ & 0.169 \\
\hline \multicolumn{4}{|c|}{$\begin{array}{l}\text { Follow-up parameters at RS diagnosis or 12-months follow-up data } \\
\text { in patients without RS: }\end{array}$} \\
\hline Creatinine level, mean \pm SD $[\mu \mathrm{mol} / \mathrm{l}]$ & $149.7 \pm 81.8$ & $124.7 \pm 65.8$ & 0.049 \\
\hline eGFR, mean $\pm \mathrm{SD}\left[\mathrm{ml} / \mathrm{min} / 1.73 \mathrm{~m}^{2}\right]$ & $53.5 \pm 29.2$ & $59.4 \pm 23.7$ & 0.183 \\
\hline Systolic blood pressure, mean \pm SD [mm Hg] & $150 \pm 13.1$ & $133.8 \pm 17.8$ & $<0.001$ \\
\hline Diastolic blood pressure, mean \pm SD [mm Hg] & $83 \pm 9.3$ & $76.8 \pm 11.6$ & 0.010 \\
\hline Change in creatinine level at follow-up vs. initial & $22.5 \pm 55.2$ & $-3.6 \pm 43.8$ & 0.002 \\
\hline Change in eGFR level at follow-up vs. initial level & $-1.8 \pm 18$ & $5.3 \pm 19.4$ & 0.044 \\
\hline Change in SBP value at follow-up vs. initial SBP & $1.3 \pm 17.6$ & $-15.8 \pm 25.8$ & 0.009 \\
\hline Change in DBP value at follow-up vs. initial SBP & $2.6 \pm 10$ & $-6.5 \pm 14.1$ & 0.010 \\
\hline
\end{tabular}

95\% Cl: $1.08-7.91 ; p=0.033)$, stent diameter $\leq 5 \mathrm{~mm}$ $(\mathrm{HR}=2.76 ; 95 \% \mathrm{Cl}: 1.09-6.97 ; p=0.031)$, and inflammatory aetiology of RAS ( $\mathrm{HR}=5.61 ; 95 \% \mathrm{Cl}$ : 1.83-17.2; $p=0.003)$ occurred as independent predictors of RS risk increase (Table IV).

The 7-year Kaplan-Meier RS-free survival rate in the whole group was $82.5 \%$ for primary and $96.5 \%$ for secondary patency. Curves differed significantly depending on the RAS aetiology (Figure $2 \mathrm{~A}$ ). The rates of freedom from RS at 1, 2, 3, and 7 years after PTA were $100 \%$ in FMD, while $95.6,92,88$, and $83.9 \%$ in atherosclerosis, as well as 71.4 , $39.7,39.7$, and $39.7 \%$ in vasculitis $(p<0.001)$.

During mean follow-up, overall $28 / 36$ (77.8\%) lesions in $24 / 30$ (80\%) patients were referred for further invasive assessment. Of those, 15 focal and 13 diffused restenotic lesions were confirmed on angiography and referred for re-PTA. The remaining 6 patients with RS, after detailed evaluation of clinical and haemodynamic data, were arranged in the observational group and continuation of medical therapy.

In patients treated with rePTA the baseline vessel diameter at the point of RS was $74.6 \pm 16.1 \%$, and it was reduced to $19.4 \pm 10 \%$ after re-intervention. Secondary success rate defined as residual diameter stenosis less than $30 \%$ was $91.7 \%$ (22 out of 24 patients).

The re-PTA intervention comprised balloon angioplasty alone in 14 lesions, drug eluting balloon in 7, bare metal stent implantation in 1 , and drug eluting stent implantation in 6.

Recurrent RS was noted in 5 out of 24 (20.8\%) patients/5 out of $28(17.8 \%)$ lesions treated with index rePTA.
The Kaplan-Meier RS-free survival rates were 93.4, 85.2 , and $84.1 \%$ for primary RS, and 99.5, 98.1, and $95.7 \%$ for secondary patency at 1,3 , and 5 years after PTA, respectively (Figure $2 \mathrm{~B}$ ).

\section{Discussion}

RAS is the most common cause of secondary hypertension with incidence estimated between $1 \%$ and $5 \%$ in the general population [22, 23]. In patients with atherosclerotic lesions recognised in coronary or supra-aortic arterial beds, the prevalence of RAS is much higher, between 10-20\% [24-26].

Invasive lesion management has been a treatment option for patients with malignant or resistant hypertension, hypertension crisis, or pulmonary flash oedema, when the effect of blood lowering treatment is suboptimal, and includes a variety of techniques such as percutaneous stent-assisted angioplasty or surgical reconstruction [27].

All endovascular procedures are affected by recurrent stenosis, and this main drawback of PTA of RAS has an average reported incidence rate of between $6.5 \%$ and $40 \%$ [18]. However, univocally different risk factors for RS in extra-coronary territory are postulated [28-30].

The effect of stent implantation in atherosclerotic origin RAS, compared to medical treatment alone, has a small impact on BP control, and an even weaker impact on renal function preservation in the majority of randomised clinical trials, but better results have been reported in single-centre cohort studies [5, 31].

Furthermore, the diagnosis of RS is limited by the blurred clinical picture. Firstly, the impact of PTA on BP 
Table IV. Univariate and multivariate Cox proportional hazards analysis for risk of restenosis. Only parameters with $p$-value $<0.1$ in a Cox univariate hazard analysis were included in a multivariate stepwise Cox proportional hazards analysis

\begin{tabular}{|c|c|c|}
\hline Parameters associated with restenosis & $\begin{array}{c}\text { Univariate Cox } \\
\text { HR }(95 \% \mathrm{Cl}) ; p \text {-value }\end{array}$ & $\begin{array}{c}\text { Multivariate Cox } \\
\text { HR }(95 \% \mathrm{Cl}) ; p \text {-value }\end{array}$ \\
\hline \multicolumn{3}{|l|}{ Baseline data } \\
\hline Age & 0.98 (0.95-1.01); 0.278 & - \\
\hline Male gender & $0.88(0.42-1.86) ; 0.750$ & - \\
\hline Vasculitis vs. other aetiologies & $9.52(3.75-24.2) ;<0.001$ & $5.61(1.83-17.2) ; 0.003$ \\
\hline Hypertension & $\mathrm{n} / \mathrm{a}$ & $\mathrm{n} / \mathrm{a}$ \\
\hline Diabetes mellitus & $1.71(0.98-3.76) ; 0.061$ & $1.91(0.78-4.65) ; 0.150$ \\
\hline Hyperlipidaemia & $0.51(0.17-1.53) ; 0.234$ & - \\
\hline Smoking history & $0.78(0.37-1.66) ; 0.523$ & - \\
\hline Renal impairment & $1.16(0.56-2.42) ; 0.688$ & - \\
\hline Previous myocardial infarction & 0.99 (0.34-2.87); 0.993 & - \\
\hline Previous percutaneous coronary intervention & $1.41(0.67-2.95) ; 0.365$ & - \\
\hline Previous coronary artery bypass grafting & $1.13(0.43-2.98) ; 0.798$ & - \\
\hline Previous peripheral revascularisation & $0.83(0.34-2.06) ; 0.705$ & - \\
\hline Previous ischaemic stroke/transient ischaemic attack & $(0.30-3.32) ; 0.994$ & - \\
\hline Coronary artery disease & $0.97(0.45-2,11) ; 0.951$ & - \\
\hline Supra-aortic artery disease & $0.75(0.36-1.56) ; 0.441$ & - \\
\hline \multicolumn{3}{|l|}{ Procedure related factors: } \\
\hline Bilateral PTA or PTA of one functioning kidney & 2.57 (1.23-5.38); 0.011 & $18.6(0.89-38.3) ; 0.058$ \\
\hline PTA of right vs. left renal artery & 0.99 (0.52-1.92); 0.989 & - \\
\hline Stenosis severity before primary PTA & $1.01(0.98-1.04) ; 0.322$ & - \\
\hline Stenosis severity after primary PTA & $1.03(0.99-1.04) ; 0.332$ & - \\
\hline Balloon angioplasty alone & $n / a$ & $n / a$ \\
\hline Drug eluting stent implantation & $0.79(0.27-2.26) ; 0.662$ & - \\
\hline Stent length & $0.96(0.87-1.05) ; 0.411$ & - \\
\hline Stent diameter $\leq 5 \mathrm{~mm}$ & 2.79 (1.29-6.02); 0.009 & 2.76 (1.09-6.97); 0.031 \\
\hline Predilatation & $1.48(1.25-4.93) ; 0.009$ & $1.48(0.67-3.26) ; 0.324$ \\
\hline Maximal inflation pressure & $1.13(1.01-1.27) ; 0.028$ & 1.15 (0.89-1.48); 0.268 \\
\hline \multicolumn{3}{|l|}{ Clinical outcome: } \\
\hline SBP at final follow-up visit & 1.03 (1.01-1.04); 0.001 & 0.98 (0.93-1.03); 0.426 \\
\hline DBP at final follow-up visit & 1.03 (1.00-1.06); 0.020 & $1.11(0.09-1.24) ; 0.052$ \\
\hline Creatinine level at final follow-up visit & $1.00(1.00-1.01) ; 0.033$ & $1.00(0.10-1.01) ; 0.772$ \\
\hline eGFR at final follow-up visit & 0.98 (0.97-1.00); 0.171 & - \\
\hline \multicolumn{3}{|l|}{$\begin{array}{l}\text { Change in BP and renal parameters at follow-up vs. } \\
\text { baseline: }\end{array}$} \\
\hline No SBP/DBP decrease of less than $\leq-1 /-2 \mathrm{~mm} \mathrm{Hg}$ & $4.19(1.91-9.23) ;<0.001$ & 4.15 (1.67-10.3); 0.002 \\
\hline Creatinine level increase $\geq 22 \mu \mathrm{mol} / \mathrm{l}$ & $1.94(0.88-4.26) ; 0.095$ & $0.20(0.02-2.18) ; 0.189$ \\
\hline eGFR increase of $\leq 0.17 \mathrm{ml} / \mathrm{min} / 1.73 \mathrm{~m}^{2}$ & 2.67 (1.19-5.98); 0.016 & 2.93 (1.08-7.91); 0.033 \\
\hline
\end{tabular}



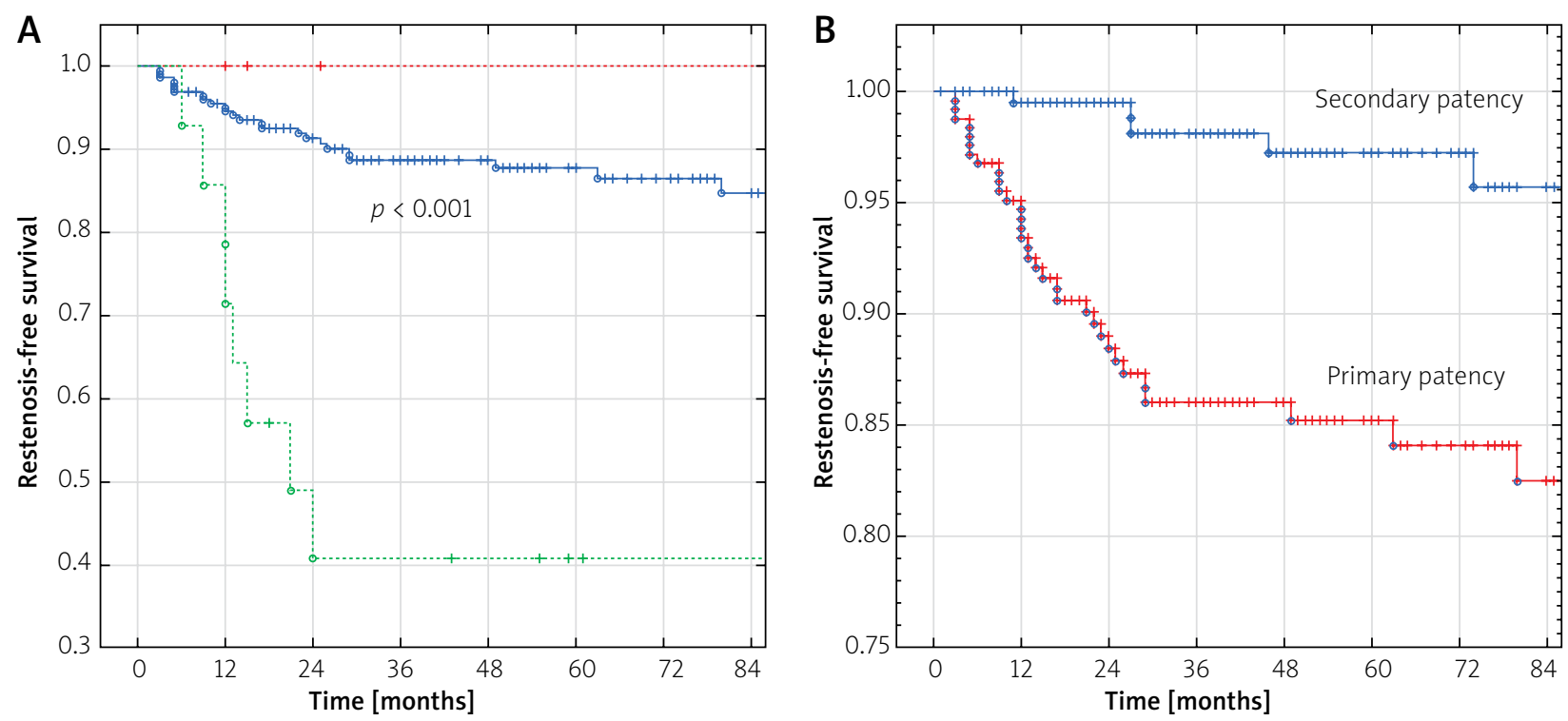

- Atherosclerotic ..... Fibromuscular dysplasia ..... Inflammatory

Figure 2. Kaplan Meier curves: A - restenosis-free survival based on the RAS aetiology, B - primary and secondary renal artery patency in the whole study group

and renal function is unpredictable and diversified; secondly, there are no pathognomonic symptoms indicative of RS; and finally, the effect of RS on clinical parameters is poorly investigated. The novelty of our present study was the identification of potential links between the change in BP and renal parameters and the incidence of RS. Our major finding is that the lack of significant decrease in either SBP (less than $-1 \mathrm{~mm} \mathrm{Hg}$ drop) and DBP (less than $-2 \mathrm{~mm} \mathrm{Hg}$ drop) at 6-12 months following successful procedure was independently related to a 4.15 -fold RS risk increase, while lack of renal function improvement (eGFR increase of less than $0.17 \mathrm{ml} /$ $\mathrm{min} / 1.73 \mathrm{~m}^{2}$ ) was associated with 2.93-fold risk of stenosis recurrence in multivariate Cox proportional hazard analysis.

In line, Zeller et al., in a group of 447 patients who underwent 619 renal artery interventions, found an RS rate of $19 \%$ at 5 years [32]. Of these RS, $81 \%$ were associated with recurrent symptoms: recurrent hypertension in $84 \%$, or continuing deterioration in renal function in $16 \%$. Also, Lederman et al. observed that RS tended to be more common among patients who had renal functional deterioration or lack of BP decrease after the PTA [13].

The index vessel diameter - another predictor of RS identified in our present study - was also reported by other authors [13, 14, 33, 34]. While stent diameter cutoff values related to RS risk differ between the studies, the general rule was that smaller vessels have a higher RS rate, e.g. in the Lederman study, the RS rate was $36.0 \%$ for vessels with a reference diameter $<4.5 \mathrm{~mm}$, compared with $15.8 \%$ in vessels with reference diameter 4.5 to $6.0 \mathrm{~mm}$, and $6.5 \%$ in vessels with reference diameter exceeding $6.0 \mathrm{~mm}(p<0.001)$ [13].
Consistently, Vignali et al. and Djavidani et al. reported a lower rate of RS in patients with stent diameter of $6 \mathrm{~mm}$ or more, compared with smaller diameters [14, 34]. Vessel size is also reflected by lower patency rates. In small-diameter renal arteries $(<3.5 \mathrm{~mm})$ treated with DES in patients with atherosclerotic renal artery stenosis, the 1-, 2-, and 5-year patency rates were $71 \%, 63 \%$, and $38 \%$, respectively [35].

The RAS disease has heterogeneous aetiology, hence both the clinical and survival outcomes differ with respect to whether arteritis, FMD, or atherosclerosis is its background [36, 37].

Iwashima et al. paid attention to differences between RS risk factors depending on the RAS aetiology. In atherosclerotic lesions, independent predictors of RS were initial degree of RAS > 90\% $(\mathrm{HR}=3.95 ; 95 \% \mathrm{Cl}: 1.14-24.95)$ as well as the presence of cardiovascular disease (2.84; 95\% Cl: 1.16-8.51) [11]. While FMD was associated with RS risk itself ( $\mathrm{HR}=2.65 ; 95 \% \mathrm{Cl}: 1.10-5.95)$, of note the stenting rate in FMD patients was $34 \%$ in this study [11].

In our present study, the seven-year Kaplan-Meier RSfree survival curves differed significantly depending on the RAS aetiology. The rates of vessel patency at 1, 2, 3, and 7 years after PTA were 100\% in FMD, while 95.6, 92, 88 , and $83.9 \%$ in atherosclerosis, as well as $71.4,39.7$, 39.7 , and $39.7 \%$ in vasculitis $(p<0.001)$.

It is well known that balloon angioplasty without stenting is sufficient in the majority FMD cases with high patency rates and cure of hypertension in the majority of patients [37]. In general, acute effect and long-term durability after PTA for FMD-related lesions are good in most treated patients, especially in the case of lesions characterised by a "string of beads" appearance limited to the 
main artery. In such cases redo procedures are needed in $6-34 \%$ of treated patients [11,37, 38].

In our study group all FMD-related lesions were eligible for revascularisation limited to balloon angioplasty alone without the need of stent implantation. However, it should be emphasised that our good results regarding acute and long-term patency of treated FMD-related lesions may as well reflect serendipity conditioned by no need of stenting and the small group of treated lesions. Indeed, these results should not be generalised and taken for granted because a $100 \%$ RS-free rate after FMD revascularisation has not been reported.

The study by Park et al. concerning long-term outcome of endovascular treatment of RAS related to Takayasu arteritis demonstrated better long-term patency and similar clinical benefit on renovascular hypertension for balloon angioplasty compared with stent placement and concluded that in this kind of RAS aetiology stent placement should be reserved for obvious angioplasty failure [36]. Furthermore, our study, with stenting in the majority of cases, indicated fast loss (60\% in 2 years) of the vessel patency in vasculitis when a stent was implanted.

In atherosclerotic RAS the other potential risk factor of RS, supported by some researchers, but not in our study, is the stent type. Published data concerning the impact of BMS and DES on restenosis prevention resulted in conflicting conclusions, favouring DES implantation in two out of three publish studies. Hence, in patients with small renal arteries the use of DES seems reasonable [12, 39, 40].

In the study by Corriere et al. decreased risk of RS was associated with preoperative statin use $(\mathrm{HR}=0.35$; 95\% Cl: 0.16-0.74; $p=0.006$ ) and increased preoperative DBP $(\mathrm{HR}=0.70$ per $10 \mathrm{~mm} \mathrm{Hg}$ increase in preoperative DBP; 95\% Cl: 0.49-0.99; $p=0.049$ ) [15]. However, statins were not confirmed in the study by Jundt et al., who reported history of stroke to be an independent risk factor of RS in patients with RAS and renal impairment at baseline [35].

In our study, patients with RS treated with repeated angioplasty showed recurrence in $20 \%$ of cases. This is in line with results of Stone et al. and Zeller et al. [16, 32].

Our patients were innumerous and were managed by different techniques, thus complex analysis is not possible. The data from Zeller et al. indicated that re-occurrence of RS was more likely in smaller vessel diameters with an incidence of $57 \%$ in $3-4 \mathrm{~mm}$; $42 \%$ in $5 \mathrm{~mm}$; $20 \%$ in $6 \mathrm{~mm}$, and $14 \%$ in $7 \mathrm{~mm}$ vessel diameters [32]. Nevertheless, repeated endovascular treatment of RS is possible and effective.

\section{Conclusions}

The average RS rate was $14 \%$, accounting for $60 \%$ in inflammatory, $17 \%$ in atherosclerotic, and $0 \%$ in FMD RAS at 24 months following PTA. Lack of the SBP/DBP and eGFR improvement following PTA, as well as inflam- matory aetiology and lower stent diameter are independently associated with increased risk of RS. Repeated PTA is effective, but recurrent RS occurs in $20 \%$ of cases.

\section{Acknowledgments}

Funding supported by a research grant from the Jagiellonian University (K/ZDS/008038).

\section{Conflict of interest}

The authors declare no conflict of interest.

\section{References}

1. Aboyans V, Ricco JB, Bartelink MEL, et al. 2017 ESC Guidelines on the Diagnosis and Treatment of Peripheral Arterial Diseases, in collaboration with the European Society for Vascular Surgery (ESVS): Document covering atherosclerotic disease of extracranial carotid and vertebral, mesenteric, renal, upper and lower extremity arteries. Endorsed by: the European Stroke Organization (ESO) The Task Force for the Diagnosis and Treatment of Peripheral Arterial Diseases of the European Society of Cardiology (ESC) and of the European Society for Vascular Surgery (ESVS). Eur Heart J 2018; 39: 763-816.

2. Witkowski A, Więcek A, Januszewicz A, et al. Indications for imaging and percutaneous angioplasty of renal artery stenosis in patients with arterial hypertension. Statement of the Polish Society of Hypertension, Polish Society of Nephrology and Polish Cardiac Society. Kardiol Pol 2010; 68: 860-7.

3. Hirsch AT, Haskal ZJ, Hertzer NR, et al. ACC/AHA Guidelines for the Management of Patients with peripheral arterial disease (lower extremity, renal, mesenteric, and abdominal aortic). J Vasc Interv Radiol 2006; 17: 1383-98.

4. Vassallo D, Kalra PA. Atherosclerotic renovascular disease - epidemiology, treatment and current challenges. Adv Interv Cardiol 2017; 13: 191-201.

5. Jenks S, Yeoh SE, Conway BR. Balloon angioplasty, with and without stenting, versus medical therapy for hypertensive patients with renal artery stenosis. Cochrane Database Syst Rev 2014; 12: CD002944.

6. Roslawiecka A, Kablak-Ziembicka A, Rzeznik D, et al. Determinants of long-term outcome in patients after percutaneous stent-assisted intervention on renal artery steno-occlusive atherosclerotic disease. Pol Arch Intern Med 2019; 129: 747-60.

7. Manolis AS, Manolis AA, Melita H. Current status of renal artery angioplasty and stenting for resistant hypertension: a case series and review of the literature. Curr Hypertens Rev 2017; 13: 93-103.

8. Kim S, Kim MJ, Jeon J, et al. Effects of percutaneous angioplasty on kidney function and blood pressure in patients with atherosclerotic renal artery stenosis. Kidney Res Clin Pract 2019; 38: 336-46.

9. Zeller T, Müller C, Frank U, et al. Survival after stent-angioplasty of severe atherosclerotic ostial renal artery stenoses. J Endovasc Therapy 2003; 58: 510-5.

10. Protasiewicz M, Kądziela J, Początek K, et al. Renal artery stenosis in patients with resistant hypertension. Am J Cardiol 2013; 112: $1417-20$.

11. Iwashima Y, Fukuda T, Yoshihara F, et al. Incidence and risk factors for restenosis, and its impact on blood pressure control after percutaneous transluminal renal angioplasty in hyperten- 
sive patients with renal artery stenosis. J Hypertens 2016; 34 : 1407-15.

12. Bradaric C, Eser K, Preuss S, et al. Drug-eluting stents versus bare metal stents for the prevention of restenosis in patients with renovascular disease. Eurolntervention 2017; 13: e248-55.

13. Lederman RJ, Mendelsohn FO, Santos R, et al. Primary renal artery stenting: characteristics and outcomes after 363 procedures. Am Heart J 2001; 142: 314-23.

14. Vignali C, Bargellini I, Lazzereschi M, et al. Predictive factors of in-stent restenosis in renal artery stenting: a retrospective analysis. Cardiovasc Intervent Radiol 2005; 28: 296-302.

15. Corriere MA, Edwards MS, Pearce JD, et al. Restenosis after renal artery angioplasty and stenting: incidence and risk factors. J Vasc Surg 2009; 50: 813-9.

16. Stone PA, Campbell JE, Aburahma AF, et al. Ten-year experience with renal artery in-stent stenosis. J Vasc Surg 2011; 53: 1026-31.

17. Silverman SH, Exline JB, Silverman LN, Samson RH. Endovascular brachytherapy for renal artery in-stent restenosis. J Vasc Surg 2014; 60: 1599-604.

18. Zeller T, Rastan A, Kliem M, et al. Impact of carbon coating on the restenosis rate after stenting of atherosclerotic renal artery. J Endovasc Ther 2005; 12: 605-11.

19. Chobanian AV, Bakris GL, Black HR, et al The Seventh Report of the Joint National Committee on Prevention, Detection, Evaluation, and Treatment of High Blood Pressure: the JNC 7 report. JAMA 2003; 289: 2560-72.

20. Mancia G, Fagard R, Narkiewicz K, et al. 2013 ESH/ESC Guidelines for the management of arterial hypertension: the Task Force for the management of arterial hypertension of the European Society of Hypertension (ESH) and of the European Society of Cardiology (ESC). J Hypertens 2013; 31: 1281-357.

21. Duan Y, Xiang F, Li Q, et al. Predictive value of duplex ultrasound for significant in-stent restenosis after percutaneous transluminal renal artery stent placement: a propensity score matching analysis. Ultrasound Med Biol 2019; 45: 913-20.

22. Safian RD, Textor SC. Renal-artery stenosis. N Engl J Med 2001; 344: 431-42.

23. Adamczak M, Zeier M, Dikow R, et al. Kidney and hypertension. Kidney Int Suppl 2002; 61: S62-7.

24. Przewłocki T, Kabłak-Ziembicka A, Tracz W, et al. Renal artery stenosis in patients with coronary artery disease. Kardiol Pol 2008; 66: 856-62.

25. Przewlocki T, Kablak-Ziembicka A, Tracz W, et al. Prevalence and prediction of renal artery stenosis in patients with coronary and supraaortic artery atherosclerotic disease. Nephrol Dial Transplant 2008; 23: 580-5.

26. Uzu T, Takeji M, Yamada N, et al. Prevalence and outcome of renal artery stenosis in atherosclerotic patients with renal dysfunction. Hypertens Res 2002; 25: 537-42.

27. Abela R1, Ivanova S, Lidder S, et al. An analysis comparing open surgical and endovascular treatment of atherosclerotic renal artery stenosis. Eur J Vasc Endovasc Surg 2009; 38: 666-75.

28. Gerardi D, Alfani A, Tesorio T, et al. Drug-coated balloon in superficial femoral artery in-stent restenosis. Adv Interv Cardiol 2018; 14: 9-14.

29. Tekieli L, Pieniazek P, Musialek P, et al. Zotarolimus-eluting stent for the treatment of recurrent, severe carotid artery in-stent stenosis in the TARGET-CAS population. J Endovasc Ther 2012; 19: 316-24.
30. Bartus K, Litwinowicz R, Sadowski J. Clinical factors predicting blood pressure reduction after catheter-based renal denervation. Adv Interv Cardiol 2018; 14: 270-5.

31. Piaggio D, Bracale U, Pecchia L, et al. Endovascular treatment versus medical therapy for hypertensive patients with renal artery stenosis: an updated systematic review. Ann Vasc Surg 2019 Jul 31. pii: S0890-5096(19)30506-0.

32. Zeller T, Rastan A, Schwarzwälder U, et al. Treatment of instent restenosis following stent-supported renal artery angioplasty. Catheter Cardiovasc Interv 2007; 70: 454-9.

33. Boateng FK, Greco BA. Renal artery stenosis: prevalence of, risk factors for, and management of in-stent stenosis. Am J Kidney Dis 2013; 61: 147-60.

34. Djavidani B, Manke C, Lenhart M, et al. Treatment of para-ostium renal artery stenoses with a new, solidly premounted balIoon expandable stent Rofo 2001; 173: 619-25.

35. Jundt MC, Takahashi EA, Harmsen WS, Misra S. Restenosis rates after drug-eluting stent treatment for stenotic small-diameter renal arteries. Cardiovasc Intervent Radiol 2019; 42: 1293-301.

36. Park HS, Do YS, Park KB, et al. Long term results of endovascular treatment in renal arterial stenosis from Takayasu arteritis: angioplasty versus stent placement Eur J Radiol 2013; 82: 1913-8.

37. Gottsäter A, Lindblad B. Optimal management of renal artery fibromuscular dysplasia. Ther Clin Risk Manag 2014; 10: 583-95.

38. Gornik HL, Persu A, Adlam D, et al. First International Consensus on the diagnosis and management of fibromuscular dysplasia. Vasc Med 2019; 24: 164-89.

39. Misra S, Thatipelli MR, Howe PW, et al. Preliminary study of the use of drug-eluting stents in atherosclerotic renal artery stenoses $4 \mathrm{~mm}$ in diameter or smaller. J Vasc Interv Radiol 2008; 19: 833-9.

40. Sapoval M, Zähringer M, Pattynama P, et al. Low-profile stent system for treatment of atherosclerotic renal artery stenosis: the GREAT trial. J Vasc Interv Radiol 2005; 16: 1195-202. 